\title{
A Mosquito Mansonia titillans (Walker) (Insecta: Diptera: Culicidae: Culicinae: Mansoniini) ${ }^{1}$
}

\author{
Diana Rojas-Araya, Derrick Mathias, and Nathan Burkett-Cadena²
}

\section{Introduction}

Approximately 25 species of the genus Mansonia Blanchard are known worldwide (Gaffigan et al. 2020). However, only two species of Mansonia are known to occur in the continental United States. Mansonia titillans (Walker) is a predominantly neotropical mosquito whose larvae and pupae attach to the roots of floating aquatic freshwater plants, particularly water hyacinth (Eichhornia crassipes) and water lettuce (Pistia stratiotes), to obtain oxygen (WesenbergLund 1918) and avoid predation (Van den Assem 1985). The females can be a nuisance because of their persistent and painful bite and are known to fly several miles from where they emerge (Morris et al. 1991). Several viruses have been isolated from wild-caught Mansonia titillans females, and this species is known to be a vector of human filarial worms (Carpenter and LaCasse 1955; Burkett-Cadena 2013).

\section{Synonymy}

Mansonia titillans (Walker 1848)_accepted name

Synonym: Culex titillans Walker 1848

\section{Distribution}

Mansonia titillans is found in scattered locations throughout the southeastern United States southward through the northern half of South America. In the United States, it has been recorded in Texas, Florida, Mississippi, Georgia, South Carolina, central Louisiana, and Alabama (Cartner et al. 2018) (Figure 1). In subtropical and temperate regions, populations of Mansonia titillans reach their greatest abundance in late summer and fall (Slaff and Haefner 1985, Lounibos and Escher 1985). This pattern is linked to the growth and survival of their host plants (Escher and Lounibos 1993), which decline in late autumn and winter, and increase in the spring. The only exception to this seasonality is if they grow in freshwater springs with relatively constant water temperature (Odum 1957). In locations with cooler temperatures, it has been reported that fourth-instar larvae are able to survive during winter periods if their host plant does not disappear completely (Torretta et al. 2006). Overwintering of this species is not well studied, but it is suspected that, like many neotropical species, they have no diapause nor fixed stage for overwintering (Garcia et al. 1995).

1. This document is EENY-765, one of a series of the Entomology and Nematology Department, UF/IFAS Extension. Original publication date October 2020. Visit the EDIS website at https://edis.ifas.ufl.edu for the currently supported version of this publication. This document is also available on the Featured Creatures website at http://entomology.ifas.ufl.edu/creatures.

2. Diana Rojas-Araya; Derrick Mathias; and Nathan Burkett-Cadena; Entomology and Nematology Department, Florida Medical Entomology Laboratory; UF/IFAS Extension, Vero Beach, FL.

The Institute of Food and Agricultural Sciences (IFAS) is an Equal Opportunity Institution authorized to provide research, educational information and other services

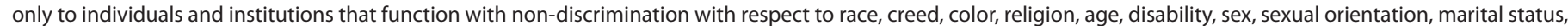

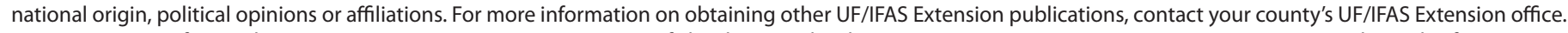
U.S. Department of Agriculture, UF/IFAS Extension Service, University of Florida, IFAS, Florida A \& M University Cooperative Extension Program, and Boards of County Commissioners Cooperating. Nick T. Place, dean for UF/IFAS Extension. 


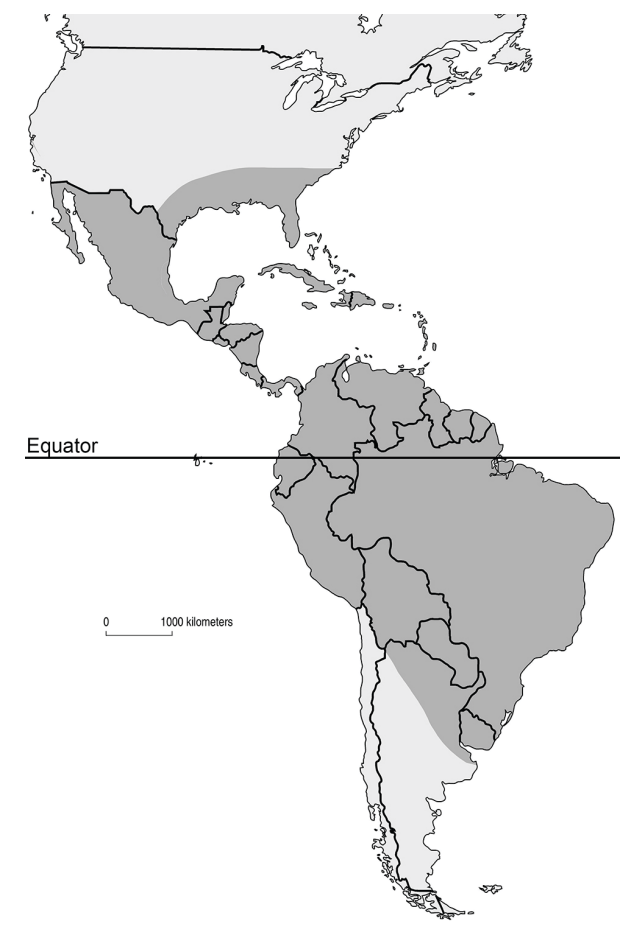

Figure 1. Approximate distribution of Mansonia titillans in North, Central and South America shaded in dark gray.

Credits: Nathan Burkett-Cadena, UF/IFAS

\section{Description}

\section{Egg}

The egg is white when initially laid and darkens during exposure to oxygen (Lounibos and Linley 1987). Each individual egg is about $1 \mathrm{~mm}$ long and cylindrical in shape, with a tapered, pointed tip that is usually darker than the rest of the egg. The egg surface is mostly covered with small protuberances. Females lay them in sticky compact masses, often arranged as a rosette (Figure 2), glued to the undersurface of floating vegetation (Mattingly 1972; Linley et al. 1986; Service 2012).

\section{Larva}

A Mansonia titillans larva is medium-sized. Head capsule width ranges (mm) of $0.30-0.35,0.47-0.58,0.79-1.06$, and 1.25-1.49 have been documented in field-collected first, second, third and fourth instar larvae (Nemjo and Slaff 1984). The larva has long antennae, which have an additional segment distal to the point of attachment of setae (hairs) 2,3-A, called the flagellum. Both setae 2,3-A are about the length of the antennal flagellum, or longer (Figure 3b). The short conical breathing siphon lacks pectin and is adapted for piercing aquatic plants to obtain air. It is heavily sclerotized, with a row of serrations on the anterior surface, and is equipped with one tooth and curved hairs that assist the larva in attaching to plants when the larva inserts its siphon (Figure $3 \mathrm{c}$, bottom right). The saddle (or segment X) bears precratal setae. The comb on segment
VIII is a single row of 6-8 slender comb scales (CS) with a single median spine (Figure 3c, top right) (Darsie and Ward 2005; Burkett-Cadena 2013).
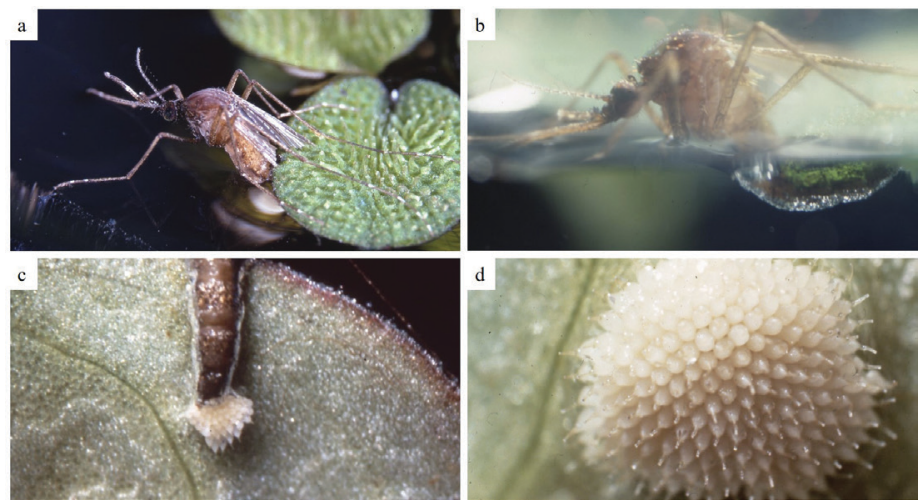

Figure 2. Female oviposition sequence (a-c) and compact egg mass (d) glued to the undersurface of floating vegetation. Photographs show a female sitting on the edge of a partially submerged leaf and extending her abdomen to the underwater portion of the leaf where she will attach her eggs (a). An air bubble (plastron) is transferred from the abdomen of the ovipositing female to surround the growing egg mass (b). The eggs are white as they are laid (c) and arranged as a rosette (d).

Credits: Phillip Lounibos, UF/IFAS
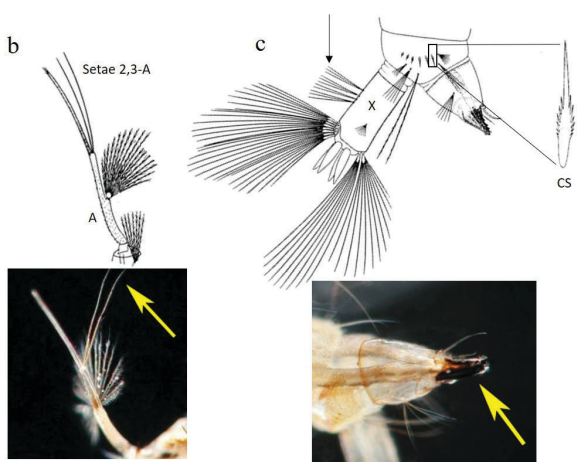

Figure 3. a. Mansonia titillans (Walker) larvae, showing modified larval siphon. b. Antenna illustration and photograph, detailing the setae 2,3-A. The antenna is labelled $A$ in the illustration. The yellow arrow points to setae 2,3-A in the photograph. c. Illustration and photograph of the posterior end of a larva. In the illustration, an arrow points to the precratal setae on abdominal segment $X$, which is labelled with $X$. Also, the detail of an individual comb scale labelled with CS is shown in the illustration. In the photograph, a yellow arrow points to the sclerotized siphon that is able to pierce plant tissue. Credits: Illustrations published in Carpenter and LaCasse (1955), larvae photograph by Nathan Burkett-Cadena, and antenna and siphon photographs by Michele Cutwa, UF/IFAS

\section{Pupa}

The pupa has two body regions: the cephalothorax (fused head and thorax) and the abdomen. The cephalothorax bears two short trumpets (openings to the respiratory system) that are heavily sclerotized and pointed for insertion into aquatic plants for respiration (Figure 4) (Service 2012). 


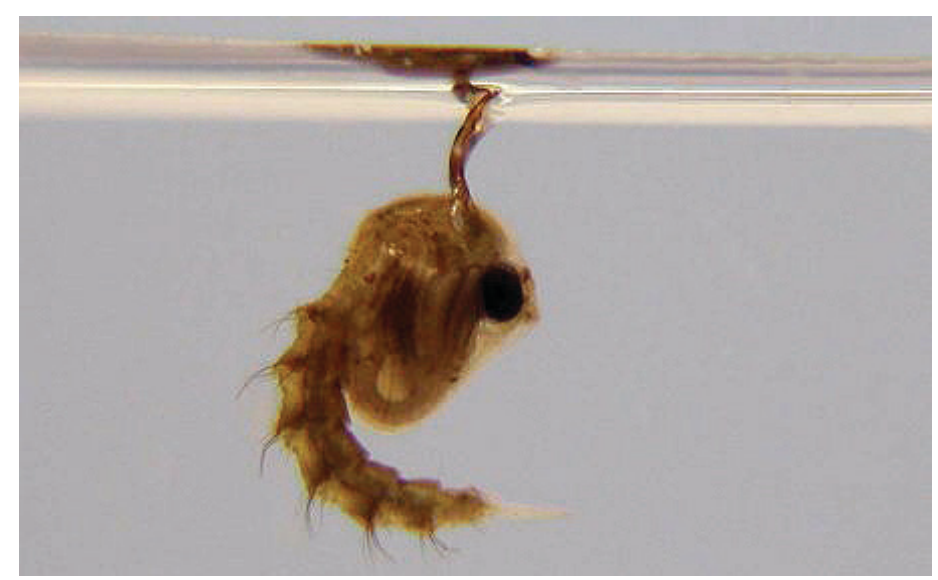

Figure 4. Mansonia dyari (Belkin, Heinemann, and Page) pupa (lateral view).

Credits: Michele Cutwa, UF/IFAS

\section{Adult}

The adult is medium-sized (female wing length of $4.0 \mathrm{~mm}$ ) with its palps, legs, wings, and body covered with a mixture of dark (usually brown) and pale (usually white or creamy) scales (Carpenter and LaCasse 1955) (Figure 5). The ventral surface (underside) of the proboscis is mostly dark scaled, and the palps are one-half the length of the proboscis (Burkett-Cadena 2013) (Figure 6). The dark legs have pale speckles and narrow pale bands at the base of each tarsal segment (Figure 7). Wings have broad pale and dark scales on the dorsal surface (Figure 8). The apex of the abdomen appears truncated from a dorsal view. The tip of abdominal tergite VII has a row of short dark spines (Figure 9), which differ in shape and number from the same structures on Mansonia dyari (Belkin, Heinemann, and Page), its closest relative in the region (Linley 1989, Darsie and Ward 2005, Burkett-Cadena 2013). Females use these spines during oviposition to clear detritus from the leaf surface to allow proper adhesion of eggs to the leaf (Linley 1989).

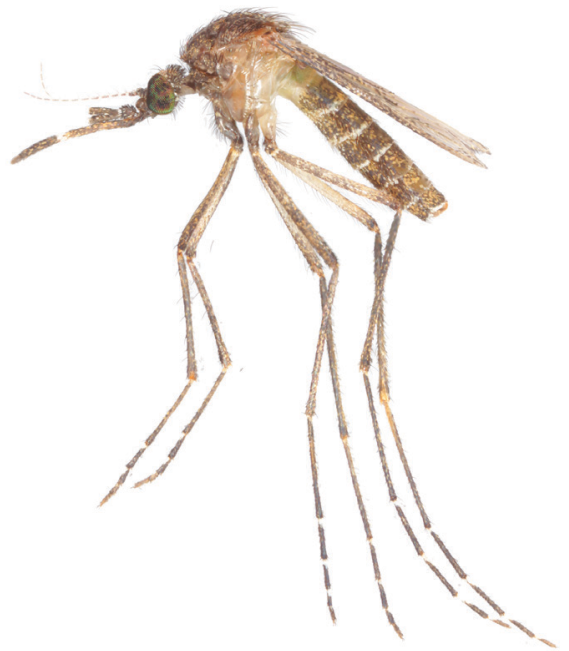

Figure 5. Mansonia titillans adult female (lateral view).

Credits: Nathan Burkett-Cadena, UF/IFAS Florida Medical Entomology Laboratory

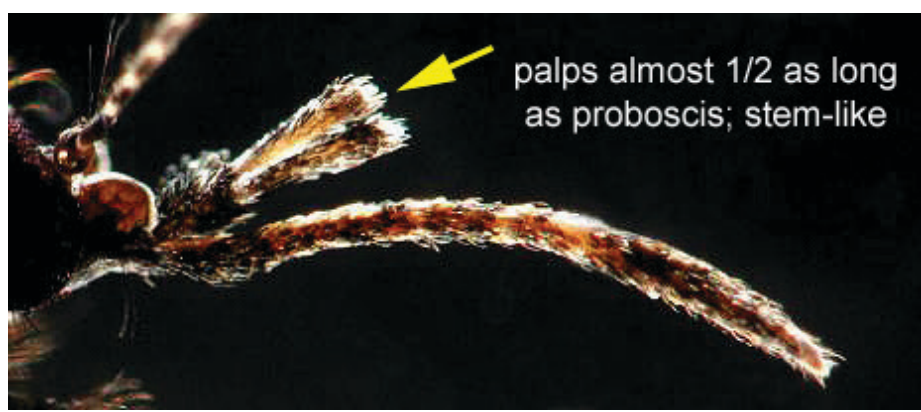

Figure 6. Mansonia titillans (Walker) adult female proboscis. Credits: Michele Cutwa, UF/IFAS Florida Medical Entomology

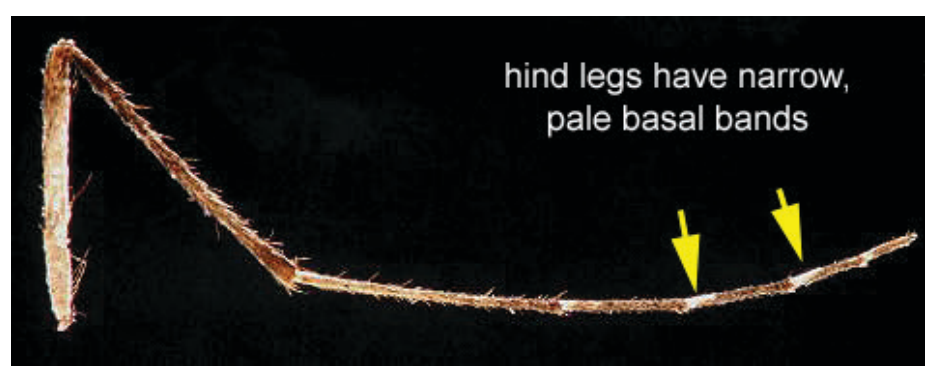

Figure 7. Mansonia titillans (Walker) adult female hind leg. Credits: Michele Cutwa, UF/IFAS Florida Medical Entomology

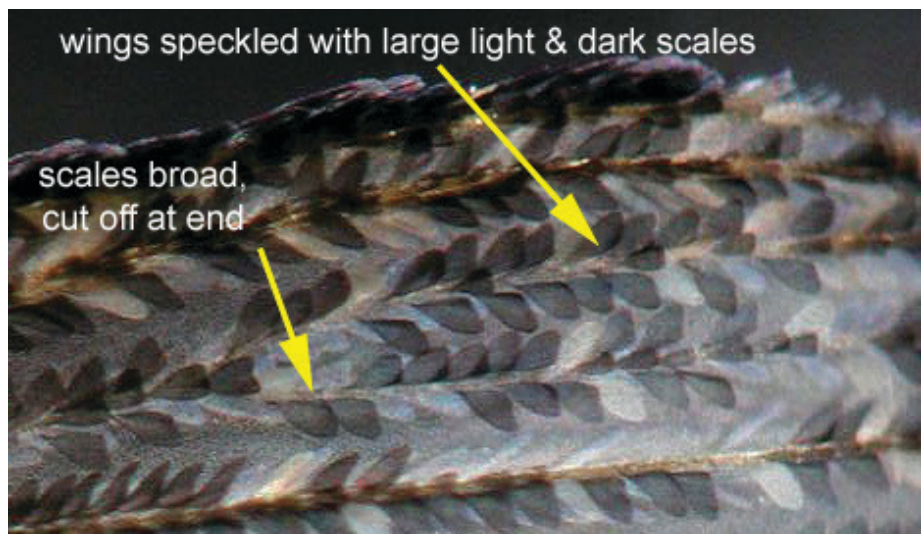

Figure 8. Mansonia titillans (Walker) adult female wing. Credits: Michele Cutwa, UF/IFAS Florida Medical Entomology

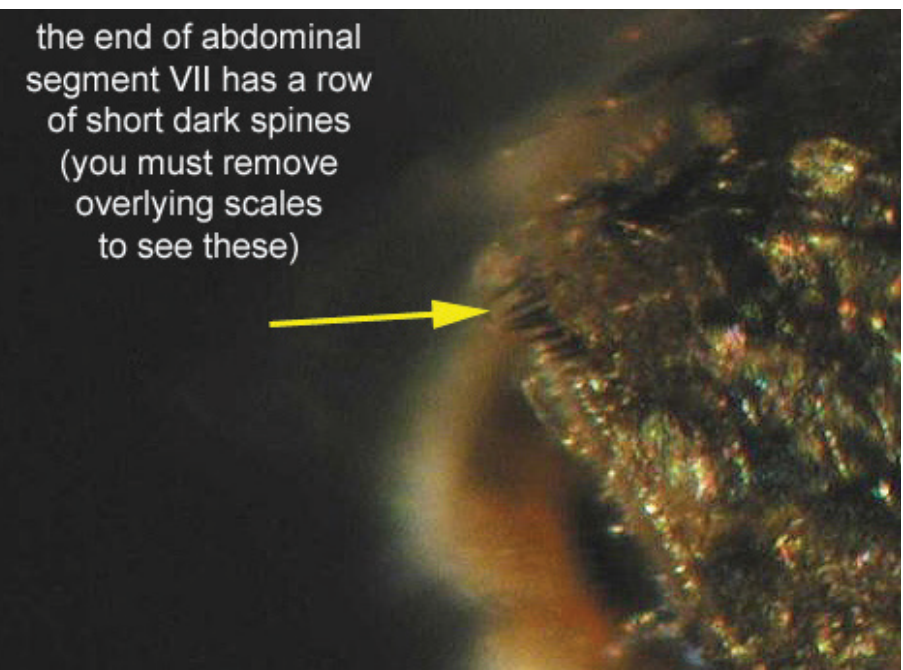

Figure 9. Mansonia titillans (Walker) adult female abdominal segment VII.

Credits: Michele Cutwa, UF/IFAS Florida Medical Entomology 


\section{Life Cycle and Hosts}

Mansonia titillans is holometabolous (undergoes complete metamorphosis) and its life cycle contains egg, larval, pupal, and adult stages. Food sources for adults include flower nectar, and in the case of females, the blood of vertebrate animals, mainly from birds and mammals (including humans) (Edman 1971, dos Santos Silva et al. 2012). Based on mark-recapture experiments, adults have a maximum and average flight distance of 3400 meters and 1300 meters, respectively (Verdonschot and Besse-Lototskaya 2014). Females bite mainly at night but will also attack during daylight. Blood-fed females, maintained in laboratory conditions at $27^{\circ} \mathrm{C}$ and light:dark cycle of $12: 12$, complete their oogenesis after 7 days (Nayar et al. 1973). Females deposit their rosette-like egg masses on the undersides of leaves of floating aquatic macrophytes (Linley et al. 1986). Adult females sit on the edge of a partially submerged leaf and extend their abdomens to the underwater portion of the leaf, where they use spines at the end of their abdomens to scratch the undersurface of leaves where eggs will be attached (Lounibos and Linley 1987).

Embryonic development takes more than 120 hours at $27^{\circ} \mathrm{C}$ (Nayar et al. 1973). Eggs are unable to withstand desiccation and will hatch after 6-10 days, depending on the temperature (Nayar et al. 1973) or will require, in laboratory conditions, 8 days at $25^{\circ} \mathrm{C}$ or 15 days at $20^{\circ} \mathrm{C}$ from oviposition until hatching (Lounibos and Dewald 1989). They obtain oxygen from an air bubble (plastron) that envelopes them, which is transferred from the abdomen of the ovipositing female (Figure $2 \mathrm{~b}$ ) to surround the growing egg mass (Lounibos and Linley 1987). Eggs maintained under light:dark cycles hatch synchronously, within 5-10 min, but under continuous light or dark, eggs become unsynchronized and hatch over a period of 2-6 h (Nayar et al. 1973). Embryos are oriented with their heads away from the water surface so that larvae emerge directly into the water (Lounibos and Dewald 1989).
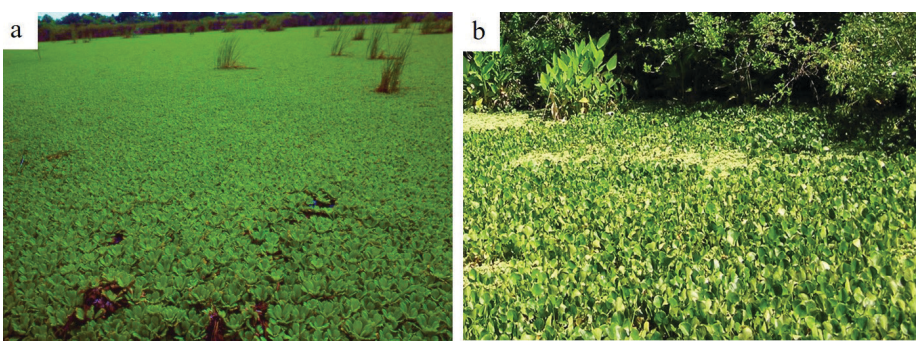

Figure 10. Water lettuce (Pistia stratiotes) (a) and water hyacinth (Eichhornia crassipes) (b) growth in permanent bodies of water. Credits: Phillip Lounibos (a) and Nathan Burkett-Cadena (b), UF/IFAS
Permanent bodies of water (lakes, ponds, canals, swamps, marshes, irrigation canals), where common floating aquatic plants such as water lettuce (Figure 10) and water hyacinth can be found, are typical habitats of immature stages (Linley et al. 1986). Larvae obtain oxygen by piercing the roots of aquatic plants using a specialized conical-shaped siphon that is heavily sclerotized. Pupae also remain attached to the roots of the plants in order to obtain oxygen. When it is time for adult emergence, pupae detach and rise to the surface (Nayar et al. 1973). They also detach themselves from plants at each molt, if disturbed (Service 2012) and likely if larvae need to move to find better food resources. Mansonia mosquitoes have three or four generations each year, depending on the weather. At summer temperatures, one generation can take 45 to 60 days, in which pupation lasts from 2 to 4 weeks (Provost 1976).

\section{Medical Importance}

The females are troublesome biters outdoors and are known to fly several miles from the marshes, ponds, and lakes they emerge from (Morris et al. 1991). Mansonia titillans is known to be a vector of filarial nematodes that cause lymphatic filariasis (Carpenter and LaCasse 1955) and is considered a potential vector of arboviruses, since wild-caught females have been found to be infected by Venezuelan equine encephalitis virus (Sudia et al. 1971), West Nile virus (Unlu et al. 2010), and St. Louis encephalitis virus (Beranek et al. 2018). However, Mansonia titillans vector competence for these arboviruses has not been assessed. Humans can protect themselves from mosquito bites by reducing the time spent outdoors at mosquito activity peak times and wearing protective clothing and mosquito repellent (CDC 2019).

\section{Surveillance and Management}

Because immature Mansonia mosquitoes usually remain submerged and attached to their host plants, localizing, and monitoring them can be a challenge (Service 2012). Immature stages can be detected by collecting potential host plants and shaking their roots into a receptacle, like a tray holding water (Silver 2008). Emergence traps can be used for adult surveillance and provide a relatively unbiased indicator of the relative abundances of their immature stages developing below (Lounibos and Escher 1985).

Using an integrated pest management strategy, which targets both the immature and adult stages, can increase the likelihood of controlling Mansonia mosquitoes. However, killing Mansonia larvae using conventional larvicides is often not practical due to the size/volume of the water 
bodies they may be found in. Reduction of their aquatic host plants through physical removal or using herbicides is the most effective way to decrease numbers of immature Mansonia mosquitoes. A caveat to this control method is that the complete removal of aquatic plants may allow some habitats to become colonized by other types of mosquitoes originally excluded by dense plant covering (Service 2012). Adults can be targeted for control by truck-based and aerial-based application of adulticides (Slaff and Haefner 1985).

Healthy aquatic environments may be able to naturally help reduce both immature and adult Mansonia mosquitoes. The larvae of Hydrophilids and Dytiscids (aquatic beetles) as well as native mosquitofish (Gambusia holbrooki) are known to consume submerged Mansonia eggs (Lounibos and Dewald 1989, Lounibos et al. 1992). Healthy aquatic habitats may also harbor insect larvae that can compete with mosquito larvae for resources or predate mosquito larvae. These aquatic habitats can also be home to dragonflies, damselflies, spiders, and frogs, which are predators of adult mosquitoes (Escher and Lounibos 1993).

\section{Selected References}

Beranek M., Gallardo R., Almirón W., and Contigiani M. 2018. "First detection of Mansonia titillans (Diptera: Culicidae) infected with St. Louis encephalitis virus (Flaviviridae: Flavivirus) and Bunyamwera serogroup (Peribunyaviridae: Orthobunyavirus) in Argentina." Journal of Vector Ecology 43:340-343.

Burkett-Cadena N. 2013. Mosquitoes of the Southeastern United States. Tuscaloosa, AL: The University of Alabama Press.

Carpenter S., and LaCasse W. 1955. Mosquitoes of North America: North of Mexico. Berkeley, CA: University of California Press.

Cartner R., Evans C., Harrison B., and Hager E. 2018. "New county records demonstrating a northern expansion of Mansonia titillans in South Carolina, USA." Journal of the American Mosquito Control Association 34:134-137.

Centers for Disease Control and Prevention (CDC), National Center for Emerging and Zoonotic Infectious Diseases (NCEZID), Division of Vector-Borne Diseases (DVBD). 2019. Prevent Tick and Mosquito Bites. https:// www.cdc.gov/ncezid/dvbd/about/prevent-bites.html
Darsie R., and Ward R. 2005. Identification and Geographical Distribution of the Mosquitoes of North America, North of Mexico. Gainesville, FL: University of Florida Press.

dos Santos Silva J., Alencar J., Martins Costa J., SeixasLorosa E., and Érico Guimarães A. 2012. "Feeding patterns of mosquitoes (Diptera: Culicidae) in six Brazilian environmental preservation areas." Journal of Vector Ecology 37:342-350.

Edman J. 1971. "Host-feeding patterns of Florida mosquitoes. I. Aedes, Anopheles, Coquillettidia, Mansonia and Psorophora." Journal of Medical Entomology 30:687-95.

Escher R., and Lounibos L. 1993. "Insect associates of Pistia stratiotes (Arales: Araceae) in southeastern Florida." Florida Entomologist 76:473-500.

Gaffigan T., Wilkerson R., Pecor J., Stoffer J., and Anderson T. 2020. Systematic Catalog of Culicidae. Walter Reed Biosystematics Unit (WRBU). http://www.mosquitocatalog. org/default.aspx

Garcia J., Campos R., and Macia A. 1995. "Observaciones ecológicas sobre Mansonia indubitans y Ma. titillans (Diptera: Culicidae) y sus enemigos naturales en Punta Lara, Argentina." Revista de la Sociedad Entomológica Argentina 54:43-50.

Linley J. 1989. “Tergal Spines of Mansonia titillans and Ma. dyari (Diptera: Culicidae) and Their Effect on a Leaf Surface during Oviposition." Journal of Medical Entomology 26:402-406.

Linley J., Linley P., and and Lounibos L. 1986. "Light and scanning electron microscopy of the egg of Mansonia titillans (Diptera: Culicidae)." Journal of Medical Entomology 23:99-104.

Lounibos L., and Escher R. 1985. "Mosquitoes Associated with Water Lettuce (Pistia stratiotes) in Southeastern Florida." The Florida Entomologist 68:169-178.

Lounibos L., and Linley J. 1987. "A quantitative analysis of underwater oviposition by the mosquito Mansonia titillans." Physiological Entomology 12:435-443.

Lounibos L., and Dewald L. 1989. "Oviposition site selection by Mansonia mosquitoes on water lettuce." Ecological Entomology 14:413-422. 
Lounibos L., Nishimura N., and DeWald L.. B. 1992. "Predation of Mansonia (Diptera: Culicidae) by native mosquitofish in southern Florida." Journal of Medical Entomology 29:236-241.

Mattingly P. 1972. Mosquito eggs. XVIII. “Genus Mansonia (subgenera Rhynchotaenia Brethes and Mansonia Blanchard) with a further note on genus Filcalbia Theobald." Mosquito Systematics 4:45-49.

Morris C., Larson V., and Lounibos L. 1991. "Measuring mosquito dispersal for control programs." Journal of the American Mosquito Control Association 7:608-615.

Nayar J., Samarawickrema A., and Sauerman D. 1973. "Photoperiodic Control of Egg Hatching in the Mosquito Mansonia titillans." Annals of the Entomological Society of America 66:831-835.

Nemjo J., and Slaff M. 1984. "Head Capsule Width as a Tool for Instar and Species Identification of Mansonia dyari, $M$. titillans, and Coquillettidia perturbans (Diptera: Culicidae)." Annals of the Entomological Society of America 77:633-635.

Odum H. 1957. "Trophic structure and productivity of Silver Springs, Florida.” Ecological Monographs 27:55-112.

Provost M. 1976. Mansonia mosquitoes: generations per year in Florida. Proceedings of 47th. Annual Meeting, Florida Anti-mosquito Association: 24-27.

Service M. 2012. Medical Entomology for Students. Fifth edition. Cambridge University Press. 303 pp.

Silver J. 2008. Mosquito Ecology: Field Sampling Methods. Third edition. Dordrecht, the Netherlands: Springer. 1477 pp.

Slaff M., and Haefner J. 1985. "Seasonal and Spatial Distribution of Mansonia dyari, Mansonia titillans, and Coquillettidia perturbans (Diptera: Culicidae) in the Central Florida, USA, Phosphate Region." Journal of Medical Entomology 22:624-629.

Sudia W., Lord R., Newhouse V., Miller D., and Kissling R. 1971. "Vector-host studies of an epizootic of Venezuelan Equine Encephalomyelitis in Guatemala, 1969." American Journal of Epidemiology 93:137-143.
Torretta J., Mulieri P., Patitucci L., Sander V., Rodríguez P., and Schweigmann N. 2006. "Winter survival of immature instars of Mansonia indubitans Dyar \& Shannon and Mansonia titillans Walker (Diptera: Culicidae), in Buenos Aires, Argentina." Memorias do Instituto Oswaldo Cruz, Rio de Janeiro 101:591-596.

Unlu I., Kramer W., Roy A., and Foil L. 2010. “Detection of West Nile virus RNA in mosquitoes and identification of mosquito blood meals collected at alligator farms in Louisiana." Journal of Medical Entomology 47:625-633.

Van den Assem J. 1958. "Some experimental evidence for the survival value of the root piercing habitats of Mansonia larvae to predators." Entomologia Experimentalis et Applicata 1:125-129.

Verdonschot P., and Besse-Lototskaya A. 2014. "Flight distance of mosquitoes (Culicidae): A metadata analysis to support the management of barrier zones around rewetted and newly constructed wetlands." Limnologica 45:69-79.

Wesenberg-Lund C. 1918. "Anatomical description of the larvae of Mansonia richiardii (Ficalbi) found in Danish freshwaters." Videnskabelige Meddelelser fra Dansk Naturhistorisk Forening 69:277-328. 